\title{
Characterization of Silk Fibroin Modified Surface: A Proteomic View of Cellular Response Proteins Induced by Biomaterials
}

\author{
Ming-Hui Yang, ${ }^{1,2,3}$ Shyng-Shiou Yuan, ${ }^{2,3,4,5}$ Tze-Wen Chung, \\ Shiang-Bin Jong, ${ }^{7,8}$ Chi-Yu Lu, ${ }^{9,10}$ Wan-Chi Tsai, ${ }^{11,12}$ Wen-Cheng Chen, ${ }^{13}$ \\ Po-Chiao Lin, ${ }^{10,14}$ Pei-Wen Chiang, ${ }^{7}$ and Yu-Chang Tyan ${ }^{3,7,10,15}$ \\ ${ }^{1}$ Instrument Technology Research Center, National Applied Research Laboratories, Hsinchu 300, Taiwan \\ ${ }^{2}$ Department of Medical Research, Kaohsiung Medical University Chung-Ho Memorial Hospital, Kaohsiung 807, Taiwan \\ ${ }^{3}$ Translational Research Center, Kaohsiung Medical University Chung-Ho Memorial Hospital, Kaohsiung 807, Taiwan \\ ${ }^{4}$ Department of Obstetrics and Gynecology, Kaohsiung Medical University Chung-Ho Memorial Hospital, Kaohsiung 807, Taiwan \\ ${ }^{5}$ School of Medicine, College of Medicine, Kaohsiung Medical University, Kaohsiung 807, Taiwan \\ ${ }^{6}$ Department of Biomedical Engineering, National Yang-Ming University, Taipei 112, Taiwan \\ ${ }^{7}$ Department of Medical Imaging and Radiological Sciences, Kaohsiung Medical University, Kaohsiung 807, Taiwan \\ ${ }^{8}$ Department of Nuclear Medicine, Kaohsiung Medical University Chung-Ho Memorial Hospital, Kaohsiung 807, Taiwan \\ ${ }^{9}$ Department of Biochemistry, College of Medicine, Kaohsiung Medical University, Kaohsiung 807, Taiwan \\ ${ }^{10}$ National Sun Yat-Sen University-Kaohsiung Medical University Joint Research Center, Kaohsiung 804, Taiwan \\ ${ }^{11}$ Department of Medical Laboratory Science and Biotechnology, Kaohsiung Medical University, Kaohsiung 807, Taiwan \\ ${ }^{12}$ Department of Laboratory Medicine, Kaohsiung Medical University Hospital, Kaohsiung 807, Taiwan \\ ${ }^{13}$ Department of Fiber and Composite Materials, College of Engineering, Feng Chia University, Taichung 407, Taiwan \\ ${ }^{14}$ Department of Chemistry, National Sun Yat-Sen University, Kaohsiung 804, Taiwan \\ ${ }^{15}$ Center of Biomedical Engineering and System Biology, Kaohsiung Medical University, Kaohsiung 807, Taiwan
}

Correspondence should be addressed to Yu-Chang Tyan; yctyan@kmu.edu.tw

Received 29 October 2013; Revised 18 January 2014; Accepted 20 January 2014; Published 25 March 2014

Academic Editor: Nihal Engin Vrana

Copyright (C) 2014 Ming-Hui Yang et al. This is an open access article distributed under the Creative Commons Attribution License, which permits unrestricted use, distribution, and reproduction in any medium, provided the original work is properly cited.

\begin{abstract}
The purpose of this study was to develop the pathway of silk fibroin (SF) biopolymer surface induced cell membrane protein activation. Fibroblasts were used as an experimental model to evaluate the responses of cellular proteins induced by biopolymer material using a mass spectrometry-based profiling system. The surface was covered by multiwalled carbon nanotubes (CNTs) and SF to increase the surface area, enhance the adhesion of biopolymer, and promote the rate of cell proliferation. The amount of adhered fibroblasts on CNTs/SF electrodes of quartz crystal microbalance (QCM) greatly exceeded those on other surfaces. Moreover, analyzing differential protein expressions of adhered fibroblasts on the biopolymer surface by proteomic approaches indicated that CD44 may be a key protein. Through this study, utilization of mass spectrometry-based proteomics in evaluation of cell adhesion on biopolymer was proposed.
\end{abstract}

\section{Introduction}

Biomaterials play important roles in regenerative medicine, tissue engineering, and drug delivery [1]. The construction of engineered scaffolds or matrices with chemical and physical surface properties that enable them to interact favorably with cells is important [2]. Cell proliferation, differentiation, and regeneration of tissues all depend upon the interactions between biomaterial surfaces and cells. For the responses of cells to biomaterials, both a cell-count method of counting nuclei stains and the MTT (3-(4,5-cimethylthiazol-2-yl)2,5-diphenyl tetrazolium bromide) or BrdU (5-bromo-2' deoxyuridine) assays are less accurate than usual studies, because small parts of cells adhere onto the biomaterial surfaces. Recently, using molecular expression-based methods such as flow cytometric analysis, immunofluorescent labeling 
and immunoblotting of cells were developed for determining the responses at cellular levels in cell adhesion onto biomaterials [3]. In addition, the identification of proteins that are involved must be known to enable the assays to be properly carried out. The advantage of using the proteomic approach is that new proteins that influence the interactions of cells and biomaterials may be found.

Multiwalled carbon nanotubes (CNTs) have a large surface area and have been extensively studied for a variety of purposes, such as sensors, fuel cells, and device patterning [4, 5]. CNTs have good biocompatibility with cells and support cellular behavior proliferation as well as differentiation of cells in the presence of induction medium. Additionally CNTs substrates show good cell viability, spreading, and physical adhesion. Silk fibroin (SF) is a protein with bulky hydrophobic domains [6] and can be easily purified as sericin-free silk-based biomaterials. Such material is highly applicable due to its low immune response characteristics. SF-based biomaterials have been investigated in the form of files, fibers, hydrogels, particles, and scaffolds [7-10] and in applications of vascular, neural, skin, bone, and cartilage tissue regeneration [11-14]. Increasingly, SF is exploited in other areas of biomedical science, as a result of new knowledge of its processing and properties like mechanical strength, elasticity, biocompatibility, and controllable biodegradability [15]. These properties of SF are particularly useful for tissue engineering.

"Proteome" and "proteomics" are relatively new words, coined by Wilkins et al. in 1996 [16]. The proteome is the entire set of proteins expressed by the genome. Proteomic analysis means a comprehensive analysis of proteins, and proteomics is the science by which proteins are comprehensively investigated with regard to their roles as functional elements. Recently, characterization of these cellular proteins by proteomic approaches has revealed that the surface charge of biomaterials defines the protein reactivity and the protein-biomaterial interaction. In the previous studies, several reports utilized proteomic approaches to explain the biomaterials-cells interaction. Titanium (Ti) is used commonly in implants and biomaterials. The surface modification was grafted by poly(sodium styrene sulfonate) (poly NaSS). The mechanisms of titanium alloy inducing platelet activation, that causes cell adsorption and proliferation, were identified by using two-dimensional gel electrophoresis (2-DE) combined with mass spectrometry, which may be related to protein adsorption on biomaterial surfaces [17]. Nanomaterials may release trace substances, which may be toxic to the surrounding cells. Human lung epithelial cells and human monocyte-derived macrophages were used to examine the cellular uptake of several forms of titanium dioxide nanoparticles and carbon nanotubes by using proteomic approaches [18]. The direct analysis of extracellular matrix (ECM) proteins from vascular aortic smooth muscle cells using a Protein Chip Bioprocessor and combined with surface enhanced laser desorption ionization time-of-flight mass spectrometry (SELDI-TOF MS) was developed by Lavigne and coworkers [19]. Their method involved a protein chip to analyze ECM proteins without transferring.
To evaluate the responses of fibroblasts to a CNTs/SF polymer surface, a quartz crystal microbalance (QCM) technique was used to quantify the mass of adhesion cells and immunochemical stains to observe the morphological changes of the cells. To apply proteomic approaches to develop a new tool for characterization of the responses of cells to biomaterials, a mass spectrometry-based profiling system was adopted. This system was able to assess characteristic proteins that were expressed due to the interactions of fibroblasts with biopolymer surfaces. Through the investigation, proteins that influence the responses and later proliferations of fibroblasts on biopolymer surfaces were identified, and CD44 was found to be involved in cell adhesion when SF interactions regulate signaling pathways.

\section{Materials and Methods}

2.1. Fabricating CNTs and Dispersing CNTs on the Electrode of QCM. The multiwalled carbon nanotubes (CNTs, 6-13 nm outer diameter, 2.5-20 $\mu \mathrm{m}$ long) were treated by refluxing in concentrated nitric acid at $85^{\circ} \mathrm{C}$ for $3 \mathrm{~h}$. When the CNTs were precipitated from the solution, the nitric acid was carefully removed. The mixture was then filtered through a $0.22 \mu \mathrm{m}$ filter under a vacuum condition. The CNTs were rinsed with D.I. water, collected, and dried in an oven at $50^{\circ} \mathrm{C}$. The surface of a $9 \mathrm{MHz}$ QCM gold electrode (ANT Tech, Taiwan) was washed with $1 \mathrm{M} \mathrm{HCl}$, rinsed with D.I. water, and dried at room temperature. The frequency of the electrode measured by the QCM (ADS, ANT Tech, Taiwan) was assigned as $F_{0}$ at the flow rate of $60 \mu \mathrm{L} / \mathrm{min}$ of phosphate buffered saline (PBS). To prepare an electrode with CNTs decoration, a solution of pluronic F68 was applied to disperse CNTs on the electrode surface. Briefly, a 1\% F68 solution was dropped onto the QCM gold electrode and then dried under oscillation. The CNTs in solution were then deposited onto the surface of the electrode and dried for further applications.

2.2. Atomic Force Microscopy Image of QCM Chip Surface. The QCM chip surfaces were analyzed by atomic force microscopy (AFM). The AFM images were acquired with a Slover PRO (NT-MDT, Russia) atomic force microscopy under ambient pressure. The semicontact mode was used with a frequency of $0.5 \mu \mathrm{m} / \mathrm{s}$ to scan an area of $50 \times 50 \mu \mathrm{m}^{2}$. The AFM probe was a golden silicon probe (NSG11, NT-MDT, Russia) with the length, width, thickness, resonant frequency, and force constant as $100 \mathrm{~mm}, 35 \mu \mathrm{m}, 2.0 \mu \mathrm{m}, 255 \mathrm{kHz}$, and $11.5 \mathrm{~N} / \mathrm{m}^{2}$, respectively.

2.3. Adsorption of SF onto CNTs Polymer Surfaces Determined by QCM Measurements and Characterized by FT-IR. Silk cocoons were purchased from a silk center in Taiwan (ShihTan, Miao-Li, Taiwan). Briefly, silk cocoons were boiled in $\mathrm{Na}_{2} \mathrm{CO}_{3}$ and extracted SFs were then dissolved in $9.3 \mathrm{M}$ $\mathrm{LiBr}$ solution. The final concentration of the SF aqueous solution was $8 \%(\mathrm{w} / \mathrm{v})$. This concentration was determined by weighing the residual solid in a known solution volume after drying at $60^{\circ} \mathrm{C}$. For fabricating a CNTs/SF electrode, $1 \%$ of the SF solution was injected into the flow loop with 
a CNTs dispersing electrode at the flow rate of $60 \mu \mathrm{L} / \mathrm{min}$. Moreover, double injections of SF solution were performed to assure that the adsorption of SF on the electrode was saturated. The frequency shifts $(\Delta F)$ were determined by the QCM and the masses of SF adsorption were recorded and calculated. To determine that the CNTs/SF layers were stably coated onto the electrode, the frequency of the electrode was measured during the flow of PBS for several minutes. The surface characterizations of the electrode decorated with CNTs, CNTs/SF were also observed using a Fourier transform infrared spectrometer (FT-IR, Spectrum One system, PerkinElmer, USA).

2.4. Culturing Fibroblasts on the CNTs and CNTs/SF Electrode Surfaces. The fibroblasts were maintained at $37^{\circ} \mathrm{C}$ and $5 \%$ $\mathrm{CO}_{2}$ in Dulbecco's Modified Eagle Medium (DMEM) supplemented with $10 \%$ fetal bovine serum (FBS, Hyclone Laboratories, Logan, UT), 1\% penicillin/streptomycin (Gibco, Grand Island, NY, USA), and $44 \mathrm{mM} \mathrm{NaHCO} 3$.

Before seeding fibroblasts, the electrodes were sterilized with $70 \%(\mathrm{v} / \mathrm{v})$ ethanol and then exposed under ultraviolet light for $30 \mathrm{~min}$. Serum-free medium containing $4 \times 10^{4}$ fibroblasts was added to each well in the presence of the aforementioned electrodes, and cells were incubated at $37^{\circ} \mathrm{C}$ with $5 \% \mathrm{CO}_{2}$ for $12 \mathrm{~h}$ for investigating the adhesion of the cells on those electrodes [20]. After incubation, the electrodes were rinsed with PBS, and then frequency shifts were measured by the QCM.

2.5. BrdU Assay. The viability of the adhered cells was determined by BrdU assay (BrdU Cell Proliferation Assay, Millipore, USA). The assay was performed according to the manufacturer's instructions. Briefly, fibroblasts were seeded into a sterile 96 -well tissue culture plate with a density of $2 \times$ $10^{5}$ cells $/ \mathrm{mL}$ in $100 \mu \mathrm{L} /$ well of appropriate cell culture media and incubated for 72 and $120 \mathrm{~h}$. Then, cells were incubated in the medium containing BrdU reagent for $2 \mathrm{~h}$. Fixing solution was added before the absorbencies were measured at $520 \mathrm{~nm}$ using an ELISA reader (Multiskan EX, Thermo Scientific, Vantaa, Finland, reference wavelength: $450 \mathrm{~nm}$ ).

2.6. Proteomic Analysis of Fibroblasts on Various Surfaces. After incubation on different material surfaces, the fibroblasts were lysed by cell lysis buffer (3500-1, Epitomics, Inc., USA), and cell lysates were centrifuged at $1500 \times \mathrm{g}$ for $10 \mathrm{~min}$ at $4^{\circ} \mathrm{C}$. The supernatants were filtered by $0.8 \mu \mathrm{m}$ filters. The protein concentrations of the cell lysate samples were measured using a fluorescence-based protein quantification detection kit (Quant-iT Fluorometer, Qubit Protein Assay Kit, Q33212, Invitrogen), and the protein concentrations were adjusted to $1 \mathrm{mg} / \mathrm{mL}$ by $25 \mathrm{mM}$ ammonium bicarbonate.

Cell lysate samples $(100 \mu \mathrm{L})$ were transferred into $1.5 \mathrm{~mL}$ Eppendorf tubes and incubated at $37^{\circ} \mathrm{C}$ for $3 \mathrm{~h}$ after mixing with $25 \mu \mathrm{L}$ of $1 \mathrm{M}$ dithiothreitol (DTT, USB Corporation, 15397). Then the cell lysate samples were reduced and alkylated in the dark at room temperature for $30 \mathrm{~min}$ after the addition of $25 \mu \mathrm{L}$ of $1 \mathrm{M}$ iodoacetamide (IAA, Amersham Biosciences, RPN6302V) in $25 \mathrm{mM}$ ammonium bicarbonate.
Approximately $10 \mu \mathrm{L}$ of $0.1 \mu \mathrm{g} / \mu \mathrm{L}$ modified trypsin digestion buffer (Trypsin Gold, Mass Spectrometry Grade, V5280, Promega, WI, USA) in $25 \mathrm{mM}$ ammonium bicarbonate was added to the cell lysate samples, which were then incubated at $37^{\circ} \mathrm{C}$ for at least $12 \mathrm{~h}$ in a water bath. Two microliters of formic acid was added to each sample before mass spectrometric analysis for protein identification.

The complex peptide mixtures were separated by RPnano-UPLC-ESI-MS/MS. The protein tryptic digests were fractionated using a flow rate of $400 \mathrm{~nL} / \mathrm{min}$ with a nanoUPLC system (nanoACQUITY UPLC, Waters, Milford, MA) coupled to an ion trap mass spectrometer (LTQ Orbitrap Discovery Hybrid FTMS, Thermo, San Jose, CA) equipped with an electrospray ionization source. For RP-nano-UPLCESI-MS/MS analyses, a sample $(2 \mu \mathrm{L})$ of the desired peptide digest was loaded into the reverse phase column (Symmetry C18, $5 \mu \mathrm{m}, 180 \mu \mathrm{m} \times 20 \mathrm{~mm}$ ) by an autosampler. The RP separation was performed using a linear acetonitrile gradient from $99 \%$ buffer A ( $100 \%$ D.I. water $/ 0.1 \%$ formic acid) to $85 \%$ buffer B (100\% acetonitrile/ $0.1 \%$ formic acid) in $100 \mathrm{~min}$ using the micropump at a flow rate of approximately $400 \mathrm{~nL} / \mathrm{min}$. The separation was performed on a C18 microcapillary column (BEH C18, $1.7 \mu \mathrm{m}, 75 \mu \mathrm{m} \times 100 \mathrm{~mm}$ ) using the nanoseparation system. As peptides were eluted from the microcapillary column, they were electrosprayed into the ESI-MS/MS with the application of a distal $2.1 \mathrm{kV}$ spraying voltage with heated capillary temperature of $200^{\circ} \mathrm{C}$. Each cycle of one full-scan mass spectrum $(\mathrm{m} / z$ 400-2000) was followed by three data dependent tandem mass spectra with collision energy set at 35\%.

2.7. Database Search. For protein identification, Mascot software (Version 2.2.1, Matrix Science, London, UK) was used to search the Swiss-Prot human protein sequence database. For proteolytic cleavages, only tryptic cleavage was allowed, and the number of maximal internal (missed) cleavage sites was set to 2. Variable modifications of cysteine with carboxyamidomethylation, methionine with oxidation, and asparagine/glutamine with deamidation were allowed. Mass tolerances of the precursor peptide ion and fragment ion were set to $10 \mathrm{ppm}$ and $0.5 \mathrm{Da}$, respectively. When the Mowse score was greater than 30 , the protein identification was defined as positive and considered significant $(P<0.05)$. Proteins were initially annotated by similar search conditions using UniProtKB/Swiss-Prot databases.

2.8. Western Blotting of Protein Expression. Confirmation of protein expression was performed by Western blotting. Each cell lysate sample $(1 \mu \mathrm{g} / \mu \mathrm{L}, 10 \mu \mathrm{L})$ was electrophoresed through a precast gel (NuPAGE Novex 4-12\% Bis-Tris Gel, $1.5 \mathrm{~mm}, 10$ wells, Invitrogen, Carlsbad, CA). Proteins were transferred from the gel to a polyvinyldifluoride (PVDF) membrane (Millipore, Bedford, CA) by means of the semidry technique using the Criterion Blotter (Bio-Rad) at $100 \mathrm{~V}$ for $60 \mathrm{~min}$ and blocked with 5\% milk in PBS (adjusted to $\mathrm{pH} 7.4$ ) containing $0.05 \%$ Tween 20 . The membrane was then incubated overnight with primary rabbit antibody $(1 \mu \mathrm{g} / \mathrm{mL})$ of anti-CD44 (1998-1, Epitomics, Inc.). 


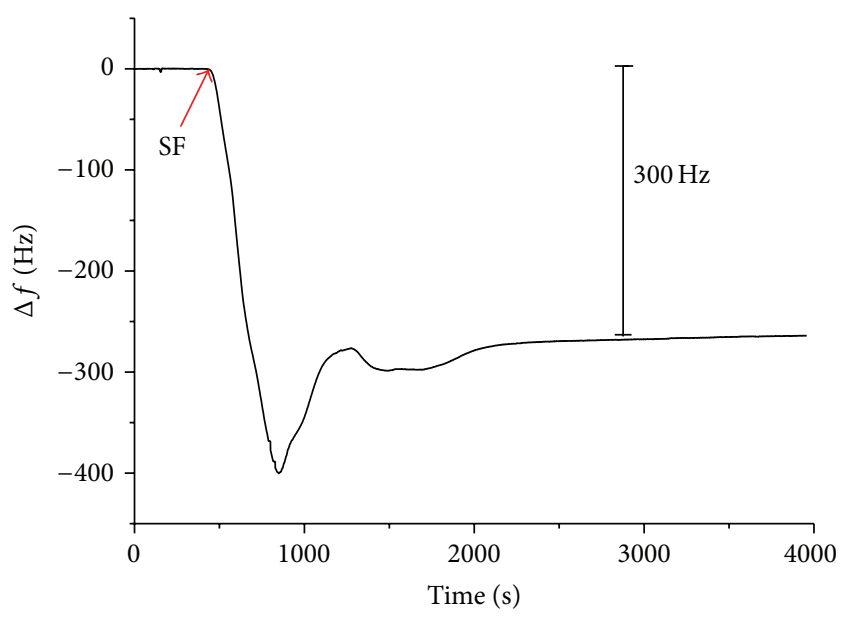

FIGURE 1: A representative of the frequency shift for preparing the electrodes decorated with CNTs/SF layer. The frequency shift of $\mathrm{CNTs} / \mathrm{SF}$ exhibited the least frequency response around $-335 \pm$ $21 \mathrm{~Hz}, n=7$.

After washing, the membrane was incubated with alkaline peroxidase-conjugated AffiniPure goat anti-rabbit IgG (111035-003, Immuno Research) for $1 \mathrm{~h}(1: 10000)$. Proteins were detected with an enhanced chemiluminescent (ECL) system, and quantitative analysis of Western blotting was carried out using the ImageQuant-TL-7.0 software, version 2010 (Amersham Biosciences).

2.9. Cell Morphology Observed by Immunochemical Staining. For cell morphology of adhered fibroblasts on the aforementioned electrodes after incubation, the electrodes were washed and fixed with $4 \%$ formaldehyde at $4^{\circ} \mathrm{C}$. The nuclei and cytoskeleton of the cells were stained with $4^{\prime}$ 6-diamidino-2-phenylindole (DAPI, 32670, Sigma-Aldrich, USA) and vimentin (Vimentin DyLight 488 Antibody, Epitomics, USA), respectively. In addition to staining with DAPI and vimentin, the anti-CD44 antibody (1998-1, Epitomics, Inc) was incubated and followed by staining with Alexa Fluor 568 goat anti-rabbit IgG (A-11011, Invitrogen). The samples were blocked with $2 \%$ bovine serum albumin (BSA, A1933, Sigma-Aldrich, USA) at room temperature for $30 \mathrm{~min}$. The cell images were observed by a microscope equipped with fluorescence light source (FLoid Cell Fluorescence Imaging Station, Invitrogen), and the cell micrographs were taken with a CCD camera.

2.10. Statistical Analysis. All calculations used the SigmaStat statistical software (Jandel Science Corp., San Rafael, CA). All statistical significances were evaluated at $95 \%$ of confidence level or better. Data are presented as mean \pm standard error.

\section{Results and Discussion}

3.1. Characterizations of Electrodes of QCM Decorated with CNTs and CNTs/SF. To prepare CNTs/SF layer, SF was
TABLE 1: Frequency shifts and mass for the adsorption of CNTs and CNTs/SF layers measured by the QCM and calculated by the Sauerbrey equation.

\begin{tabular}{lcc}
\hline Adsorption polymer & $\Delta F(\mathrm{~Hz})$ & $\Delta m(\mathrm{ng})$ \\
\hline CNTs & $-2004 \pm 33$ & $1377 \pm 23$ \\
CNTs/SF & $-335 \pm 21$ & $231 \pm 30$ \\
\hline
\end{tabular}

Data are expressed as mean \pm standard error, $n=7$.

adsorbed onto a CNTs electrode surface using the layerby-layer technique [21, 22]. For each tested biopolymer, the frequency shifts dropped sharply, as it was absorbed onto the electrode surface (Figure 1). The theory for QCM detections can be described by the Sauerbrey equation, Sauerbrey equation in gas phase. $\Delta F$ is the frequency shift $(\mathrm{Hz}) ; F$ is basic oscillation frequency of piezoelectric quartz $(\mathrm{Hz}) ; A$ is the active area of QCM $\left(\mathrm{cm}^{2}\right) ; \Delta M$ is the mass change on QCM (g). Consider the following:

$$
\Delta F=-2.3 \times 10^{-6} \frac{F^{2} \Delta M}{A},
$$

which gives the mass change as proportional to the shift in the oscillation frequency of the piezoelectric quartz crystal [20]. QCMs with electrodes have been widely studied in several fields such as environmental protection, medicine, and biotechnology. Additionally, monitoring biomolecular interactions in immunology and investigating cell-substrate communications have been extensively studied $[6,7]$. Recently, modifications of electrodes with various biopolymers of QCM have been used to detect the adhesion of cells [20]. The QCM frequency variation after CNTs-biopolymer formation was lowered to around $2.3 \mathrm{kHz}$. Table 1 presents the frequency responses and mass to the absorption of CNTs and CNTs/SF by using the Sauerbrey equation [23]. CNTs exhibited the strongest frequency responses upon deposition on the electrode $(-2004 \pm 33 \mathrm{~Hz}, 1377 \pm 23 \mathrm{ng}, n=7)$ while CNTs/SF exhibited the least frequency response $(-335 \pm 21 \mathrm{~Hz}, 231 \pm$ $30 \mathrm{ng}, n=7)$.

To investigate the topology characteristics of the surface, AFM was used to observe the QCM chip surface. In Figure 2, the image of the topographical map taken in the semicontact mode of a $50 \times 50 \mu \mathrm{m}^{2}$ zone is shown. Figure $2(\mathrm{a})$ is a surface image of the QCM chip, and Figure 2(b) shows the CNTs surface. This impressive image in Figure 2(b) shows the surface roughness with a mean depth of about $2.3 \mu \mathrm{m}$. Certainly, a rough surface may provide the opportunity to increase the reaction surface and the effectiveness of cell adhesion.

Modified surfaces of electrodes of QCM were also routinely characterized using FT-IR spectrum. Figure 3 displays the characteristics of the FT-IR spectra of the aforementioned polymers. In the absorption curve of CNTs, the broad band at $3400 \mathrm{~cm}^{-1}$ was attributed to the $\mathrm{OH}$ functional group from F68, a dispersing agent for CNTs, owing to its polyethylene oxide- (PEO-) polypropylene oxide structure [4]. The absorption bands at 1640 and $1460 \mathrm{~cm}^{-1}$ were assigned to $\mathrm{C}=\mathrm{O}$ stretching and $\mathrm{CH}_{2}$ deformation in carboxylic acid, which were attributed to the acid treatment of the CNTs 


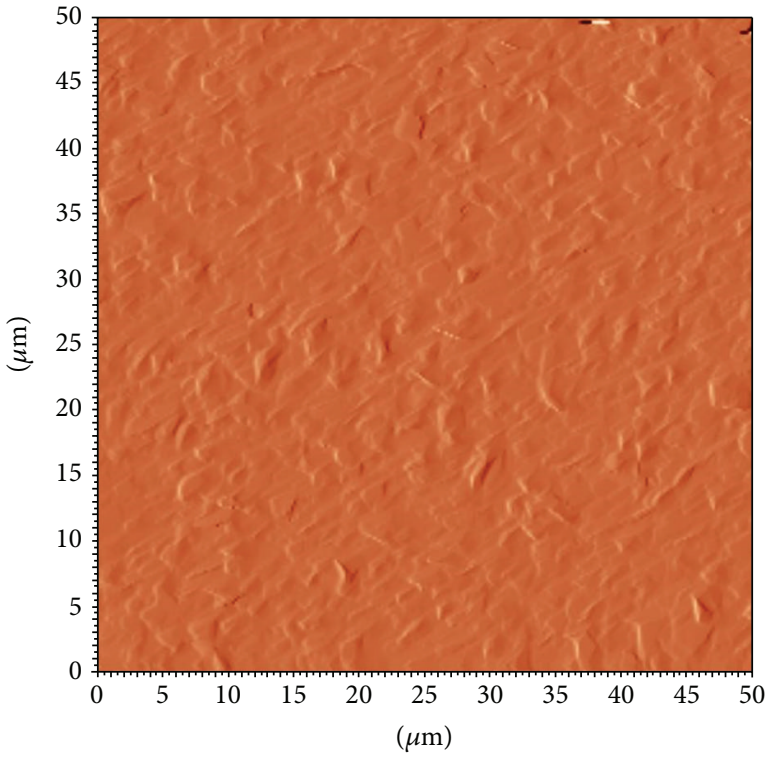

(a)

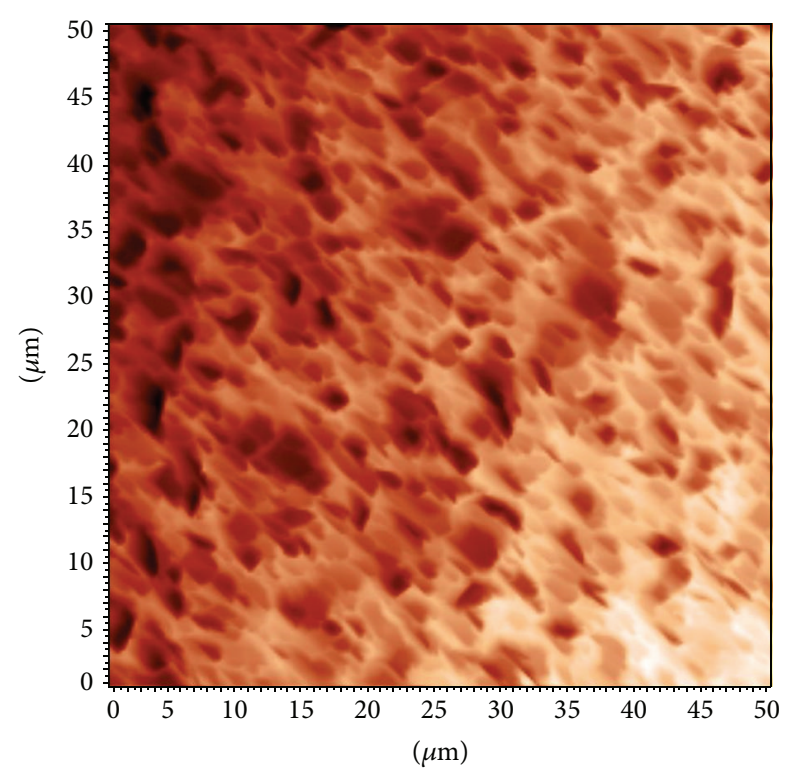

(b)

Figure 2: AFM images of the QCM chip. (a) Blank, $50 \times 50 \mu \mathrm{m}$, (b) CNTs, $50 \times 50 \mu \mathrm{m}$. AFM measurements could also be used for measuring the surface roughness of the QCM chip. The mean surface roughness was 1.0 and $2.3 \mathrm{~nm}$ for blank and CNTs surfaces, respectively.

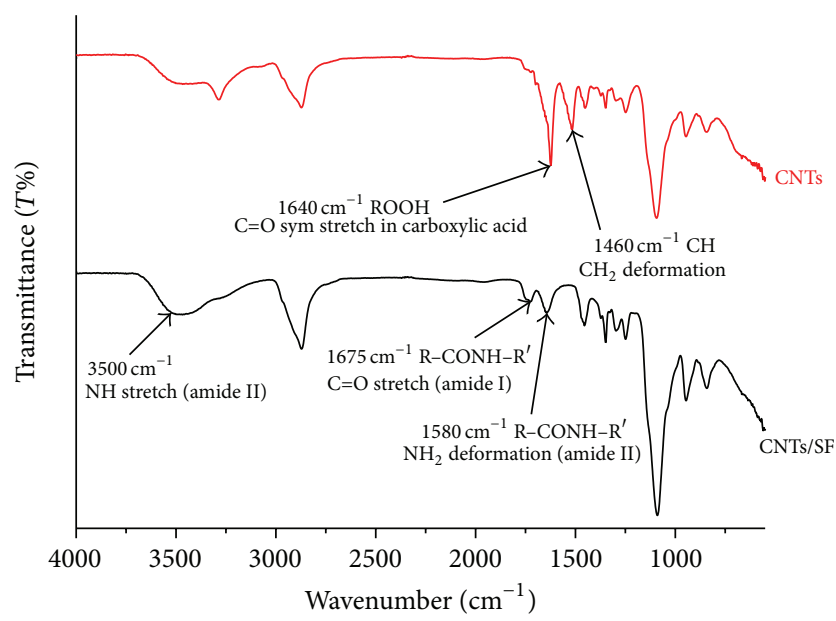

FIgURE 3: The ATR-FTIR transmission spectra of the CNTs and CNTs/SF layers decorated on electrodes of QCM. The peaks at $1580 \mathrm{~cm}^{-1}$ and $1675 \mathrm{~cm}^{-1}$ in the spectra were attributed to amide II and amide I, confirming the presence of amide I and II in SF modified surface.

[24]. The absorption band at $3500 \mathrm{~cm}^{-1}$ in the second curve corresponds to a NH stretch of SF. The peaks at $1580 \mathrm{~cm}^{-1}$ and $1675 \mathrm{~cm}^{-1}$ in the spectra of the SF surface were attributed to amide II (R-NHR', $\mathrm{NH}_{2}$ deformation, $\mathrm{N}-\mathrm{H}$ bending, and $\mathrm{C}-\mathrm{N}$ stretching) and amide $\mathrm{I}\left(\mathrm{R}-\mathrm{CONHR}{ }^{\prime}, \mathrm{C}=\mathrm{O}\right.$ stretching), respectively, confirming the presence of amide I and II in SF [25]. These results indicate the presence of $\mathrm{O}=\mathrm{C}-\mathrm{NH}$ species, which are derived from carboxylic acid and amide structures. Accordingly, the polycomplex between CNTs and SF was formed when amino groups in SF formed complexes with carboxyl groups in CNTs [26]. The spectra indicated that the electrodes were successfully decorated with CNTs and CNTs/SF biopolymers.

3.2. Quantitative Analysis of Fibroblasts Adhesion on Electrodes. To investigate the adhesion of fibroblasts onto electrodes decorated by CNTs and CNTs/SF polymer surfaces, fibroblasts were incubated on the electrodes for $12 \mathrm{~h}$. Since the adsorption of various proteins of bovine serum onto the aforementioned surfaces may influence cell adsorption behaviors, a serum-free medium was used in the cell culture. The cultivation of fibroblasts under serum-free conditions for $12 \mathrm{~h}$ herein prevented the apoptosis and proliferation of cells [27]. The results concerning the adhesion of fibroblasts onto the electrode of QCM that was decorated by CNTs or CNTs/SF were obtained from the frequency shifts [20]. The frequency shifts for nonmodified surfaces, CNTs-coated electrodes, and CNTs/SF-coated electrodes were $-16.05 \pm$ $0.44,-24.85 \pm 0.30$, and $-29.43 \pm 0.77 \times 10^{3} \mathrm{~Hz}$; the attached cell masses corresponding to those surfaces were $11.02 \pm 0.30$, $17.07 \pm 0.21$, and $21.52 \pm 0.49 \times 10^{3} \mathrm{ng}$ (Table $2, P<0.001$, $n=10$ ), respectively. The amount of fibroblasts that adhered to the CNTs/SF-coated electrode significantly exceeded that coated with either of the other surfaces. The mass of the fibroblasts that adhered to the CNTs/SF-coated electrode was calculated markedly to exceed that of those that adhered to the other surfaces, such as the CNTs polymer surface. In this investigation, the results obtained using the QCM technique to examine the adhesion of fibroblasts to the polymer-coated surfaces of the electrodes were consistent with others [20].

3.3. BrdU Cell Proliferation Assay. The surface modifications were adopted to evaluate cell viability by BrdU cell proliferation assay. The BrdU cell proliferation assay is an artificial 
TABLE 2: Frequency shifts of QCM and weights of adhered fibroblasts on the electrodes decorated with nonmodified surface, CNTs, and CNTs/SF layers for $12 \mathrm{~h}$ of cell incubation.

\begin{tabular}{lcc}
\hline Cell adhesion & $\Delta F\left(\times 10^{3} \mathrm{~Hz}\right)$ & $\Delta m\left(\times 10^{3} \mathrm{ng}\right)$ \\
\hline Nonmodified surface & $-16.05 \pm 0.44$ & $11.02 \pm 0.30$ \\
CNTs & $-24.85 \pm 0.30^{*}$ & $17.07 \pm 0.21^{*}$ \\
CNTs/SF & $-29.43 \pm 0.77^{*}$ & $21.52 \pm 0.49^{*}$ \\
\hline
\end{tabular}

Data are expressed as mean \pm standard error, $n=10,{ }^{*} P<0.001$ ( $t$-test).

nucleoside that is an analogue of thymidine and used to detect in vitro cell proliferation rates $[28,29]$. Figure 4 presents the result of the BrdU cell proliferation assay. On day one, no significant difference existed between the aforementioned nonmodified (polystyrene) and CNTs polymer surfaces, but the difference between the CNTs/SF and CNTs polymer surfaces was significant $(P<0.05)$. The number of adherent cells on the CNTs/SF polymer surface was 1.22 times that on the CNTs polymer surface (OD intensity: CNTs polymer surface, 0.0669; CNTs/SF polymer surface, 0.0816). This result of the BrdU assay is consistent with the shifts in the frequency of the QCM (different by a factor of 1.26-fold, Table 2, $\Delta m$ ). Since the number of absorbed cells may vary among plates, normalization is required. Therefore, data after three and five days were compared with those after one day. On day three, the amount of fibroblasts that adhered to the CNTs/SF polymer surface notably exceeded the numbers on the other surfaces. Almost 37\% more cells were present on CNTs/SF polymer surface than on the original nonmodified surface, while only $9 \%$ of cells were increased on the nonmodified surface, and no significant difference was observed between the CNTs polymer surface and the nonmodified surface. On the fifth day, regardless of whether the number of cells had greatly increased, the percentage difference between the number of newly synthesized cells on the nonmodified surface and that on the CNTs polymer surface was the same as that on the third day (6\%). Nevertheless, the difference between the number of cells on the CNTs/SF polymer surface and that on the nonmodified surface had increased from 28 to $41 \%$. Hence, the results demonstrate that cells on the CNTs and nonmodified surface grew at similar rates while those on the CNTs/SF polymer surface grew more rapidly. These results provided the evidence that SF accelerated adult cell proliferation.

3.4. Results of Proteomic Analysis. To investigate the effect of CNTs/SF polymer surface on fibroblasts, a proteomic approach, such as RP-nano-UPLC-ESI-MS/MS analysis, was utilized to analyze cell lysates. The traditional method uses individual antibodies to evaluate the response of a cell to a surface, but the proteomic approach can be used to analyze an enormous number of proteins simultaneously. In this study, fibroblasts were incubated on various modified surfaces with serum-free medium. After $12 \mathrm{~h}$, the cells were lysed, and the cell lysates were digested by trypsin, generating tryptic peptides that were subsequently analyzed by RPnano-UPLC-ESI-MS/MS. The RP-nano-UPLC-ESI-MS/MS

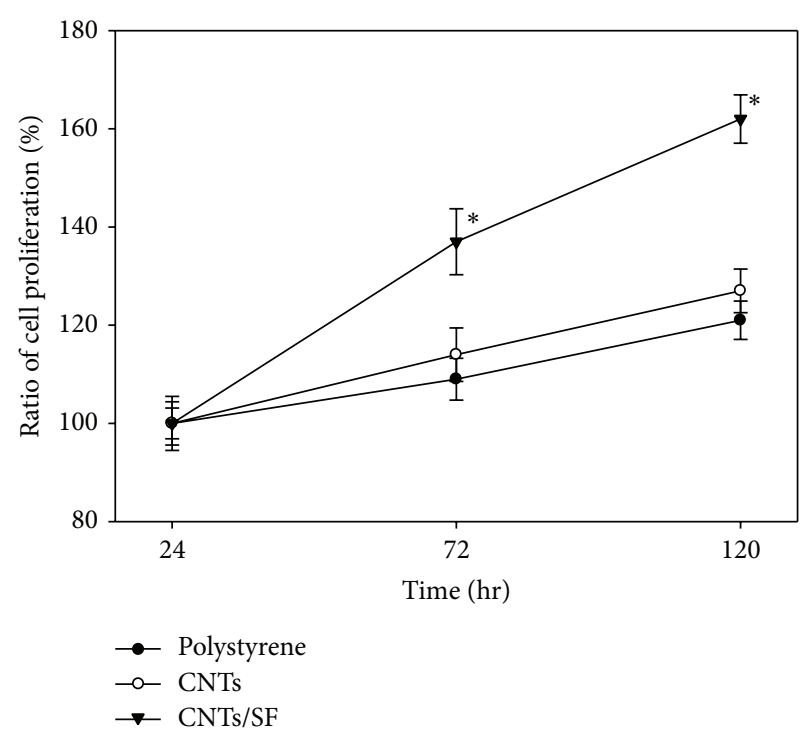

Figure 4: Proliferation (BrdU) test of fibroblasts on surfaces of polystyrene, CNTs and CNTs/SF. (polystyrene served as a control, $n=10$, mean \pm standard error, ${ }^{*} P<0.05$, $t$-test $)$.

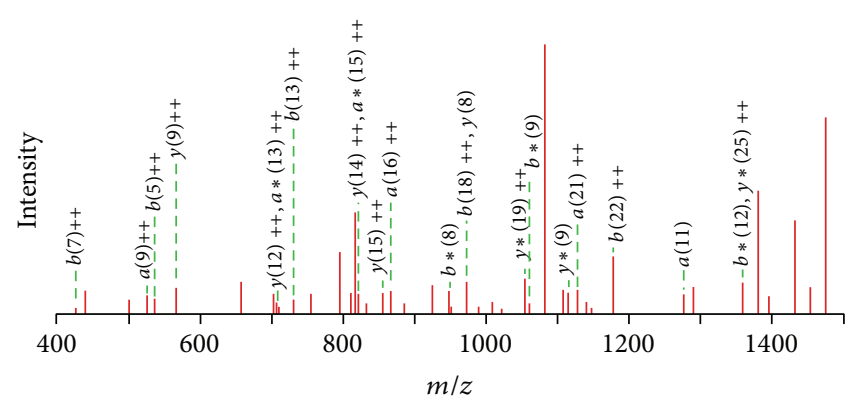

FIGURE 5: MS/MS spectrum of peptide from the fibroblasts incubated on CNTs/SF polymer surface. The amino acid sequence of the tryptic peptide is R.TPQIPEWLIILASLLALALILAVCIAVNSRRR.C $(m / z=1196.02,+3$, from CD44). Interpretation of the complete $y$ ion and $b$-ion series provides the peptide sequences as shown.

approach is perhaps the most representative method in proteome research. The fragmentation spectra obtained by the RP-nano-UPLC-ESI-MS/MS analysis in gradient detection mode were compared with a nonredundant protein database using Mascot software. When a protein was identified by three or more unique peptides, no visual assessment of spectra was conducted and the protein was considered to be present in the sample. Figure 5 shows typical MS/MS spectrum of the identified peptides. The MS/MS spectrum represents the amino acid sequence of tryptic peptide, which is triply charged peptides with $\mathrm{m} / \mathrm{z}$ of 1196.02 . The amino acid sequence of the tryptic peptide is TPQIPEWLIILASLLALALILAVCIAVNSRRR. These peptides originated from CD44, and the interpretation of the complete $y$-ion and $b$-ion series provides the peptide sequence as shown.

The database search resulted in 127 proteins and most of these were identified at the minimal confidence level, which was only one unique peptide sequence matched. 

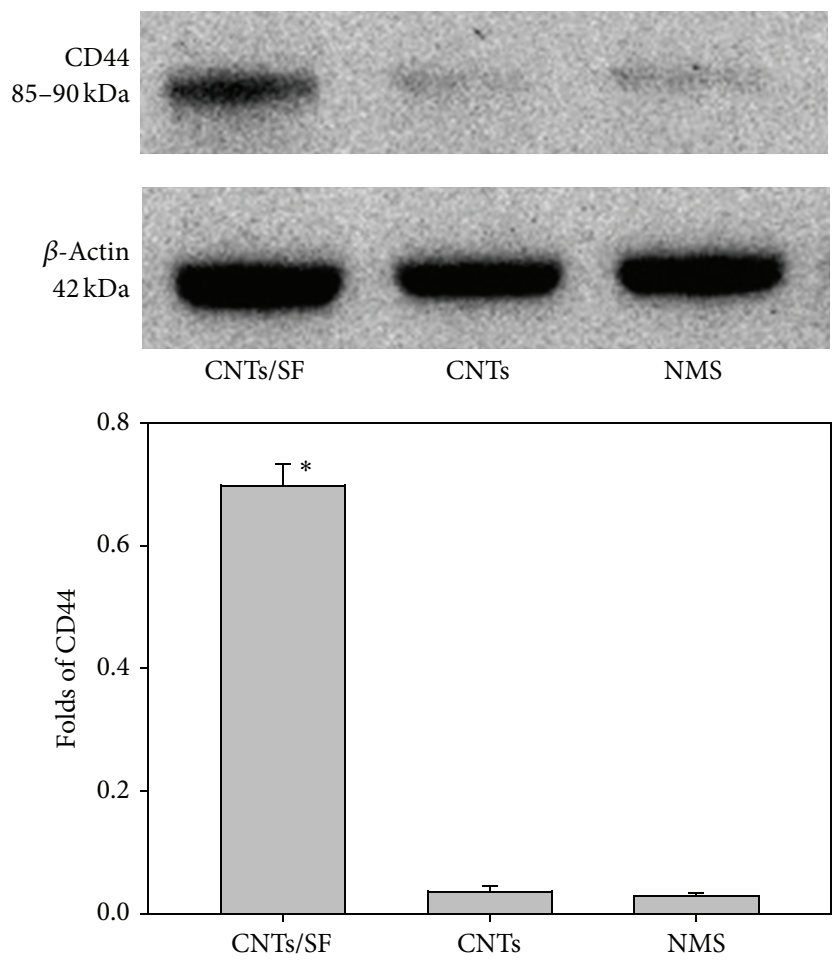

FIgURE 6: Immunoreactive bands of CD44 and $\beta$-actin from fibroblast cells cultured on surfaces of CNTs/SF, CNTs, and NMS (nonmodified surface). The quantitative analysis of Western blotting was carried out using the ImageQuant-TL-7.0 software. These values that refer to the expression of $\mathrm{CD} 44$ were normalized by the expression of beta-actin.

Experimental results reported a total of 17 protein identifications with higher confidence levels (Table 3, at least three unique peptide sequences matched), in which CD44 exhibited significant differences between the CNTs/SF and CNTs or nonmodified surfaces. CD44 was involved in cell differentiation, division, and cycle regulation, which was only found in the cell lysate samples from the CNTs/SF polymer surface and selected for validation by Western blot analysis and fluorescence image.

It has been well known that collagen plays important roles in cell adhesion progress [30-33]. In addition, other ECM proteins, such as lamina and fibronectin, were also involved in cell adhesion progress $[33,34]$. The aim of this study was to develop a mass spectrometry-based analysis platform and to map the potential proteins and effective pathways associated with cell adsorption on a SF-surface. Thus, the influences of aforementioned proteins on cell adhesion were excluded in our study. Table 4 shows the identified peptides and ontologies of CD44. Proteins were initially annotated by similarity searches using Swiss-Prot/TrEMBL and Bioinformatic Harvester EMBL databases; then, the known functions of the protein could be examined.

CD44 forms a ubiquitously expressed family of cell surface adhering molecules. It is a cell surface glycoprotein that participates in cell-cell and cell-matrix interactions, cell adhesion, and migration. The CD44 gene has only been detected in the higher levels of organisms and the amino acid sequence of the molecule is conserved among mammalian species. CD44 participates in adhesion and migration by binding to SF and other molecules in the ECM [35]. The main ligand of CD44 is hyaluronic acid (HA), an integral component of the ECM. Other CD44 ligands include osteopontin, serglycin, collagens, fibronectin, laminin, SF, and matrix metalloproteinases (MMPs) [36]. The CD44 transmembrane glycoprotein family adds new aspects to these roles by participating in signal transduction processes, which include the establishment of specific transmembrane complexes, and signaling a cascade organizer associated with the actin cytoskeleton [37]. CD44 may function as cellular growth factors, which may be important in tumor metastasis [38].

To validate the influence of $\mathrm{CD} 44$ for fibroblast adhesion on the CNTs/SF polymer surface, the cells were blocked by a CD44 antibody and the cell adhesion on the CNTs/SF polymer surface was measured by the QCM technique. When fibroblasts were preincubated with the CD44 antibody, the frequency shift was reduced (from $-29.43 \pm 0.77 \times 10^{3} \mathrm{~Hz}$ to $-23.64 \pm 0.58 \times 10^{3} \mathrm{~Hz}$ ). The result of significantly decreasing the weight of the blocked fibroblasts adhering to CNTs/SF polymer surface was obtained. Through this experiment, CD44 was confirmed to play roles on the cell adhesion which may be associated with the cell adsorption pathway on cell$\mathrm{CNTs} / \mathrm{SF}$ polymer surface interactions.

To confirm proteins identified by RP-nano-UPLC-ESIMS/MS, Western blot analysis was applied to detect the candidate protein that may be associated with cell adhesion/growth pathways on the CNTs/SF polymer surface. Figure 6 presents representative results of the Western blot analyses of cell lysates. CD44 was detected strongly in the cell lysates from the CNTs/SF polymer surface, which is valuable in confirming the SF-induced cell adhesion. In Figure 6, the $\beta$-actin was used as a marker for concentration normalization. Compared with the results of Western blotting, the concentration of CD44 in cell lysates from the CNTs/SF polymer surface was 23-fold more than those from nonmodified and CNTs polymer surfaces. This comparison was made using the quantitative analysis software ImageQuant-TL-7.0, and the $P$ value was less than 0.05 .

3.5. Cell Morphology by Fluorescence Microscopy. Fibroblasts were cultured in the medium with CD44 antibody onto $\mathrm{CNTs} / \mathrm{SF}$ polymer surfaces. The cells were observed by immunochemical staining under fluorescence microscopes to determine the morphology of the adhering fibroblasts. In Figure 7 ((a) CNTs polymer surface; (b) CNTs/SF polymer surface; DAPI, blue; vimentin, green; CD44, red; 600X, scale bar: $67 \mu \mathrm{m}$ for panel $\mathrm{A}, 100 \mu \mathrm{m}$ for panel B), the cell fluorescence images showed that CD44 was present in the cell nucleus and membrane. In the present work, we show that the CD44 protein localizes to the nucleus and colocalizes with actin in the external side of plasma membrane protrusions. The cell images showed that the adopted antibodies successfully entered into cells and have the right localization. The CD44 protein-protein interaction pathways were performed 


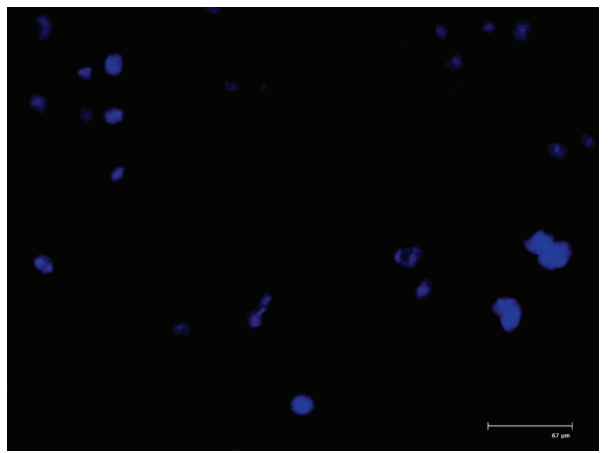

DAPI

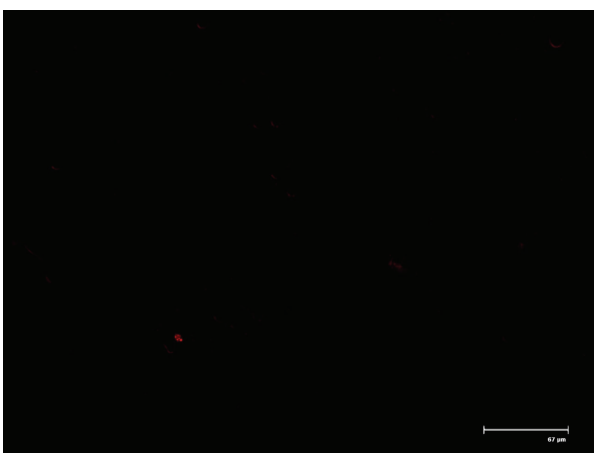

CD44

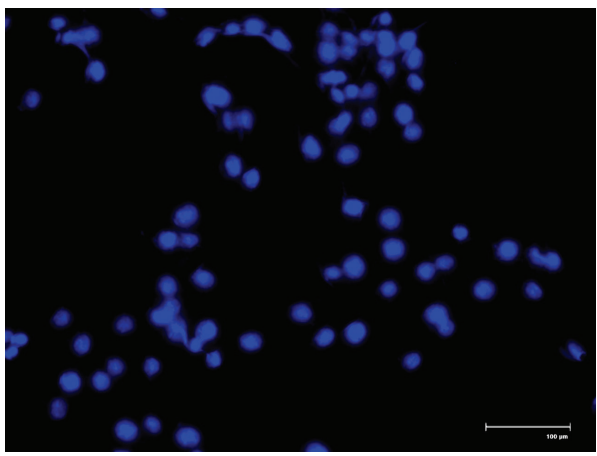

DAPI

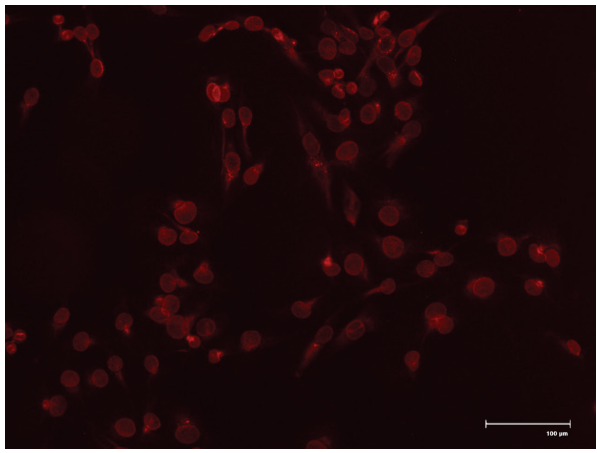

CD44

(a)

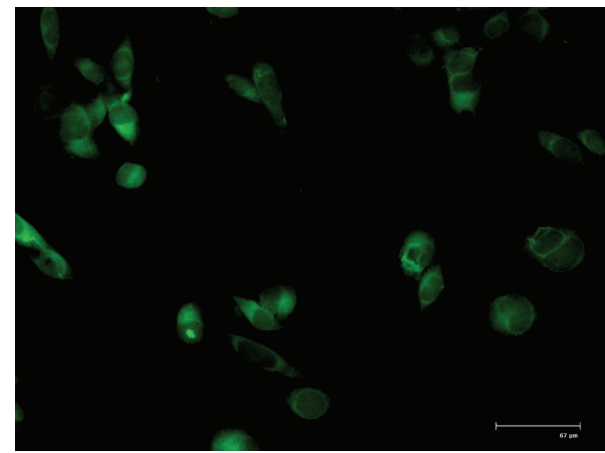

Vimentin

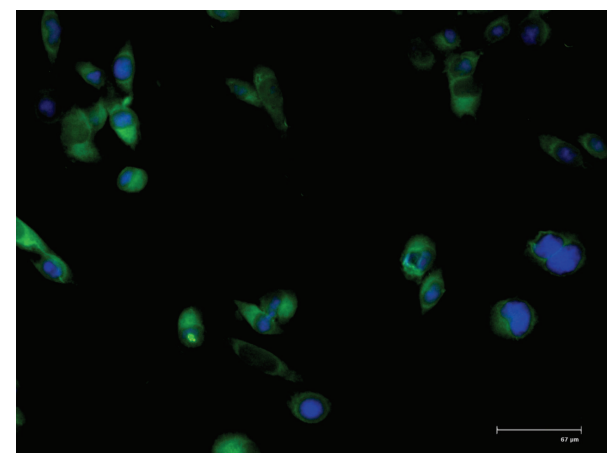

Merge

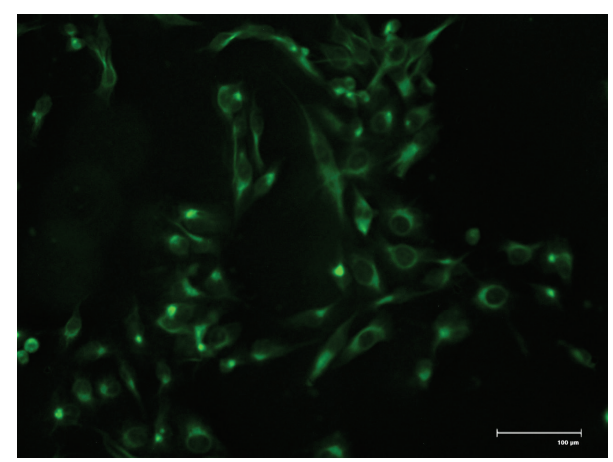

Vimentin

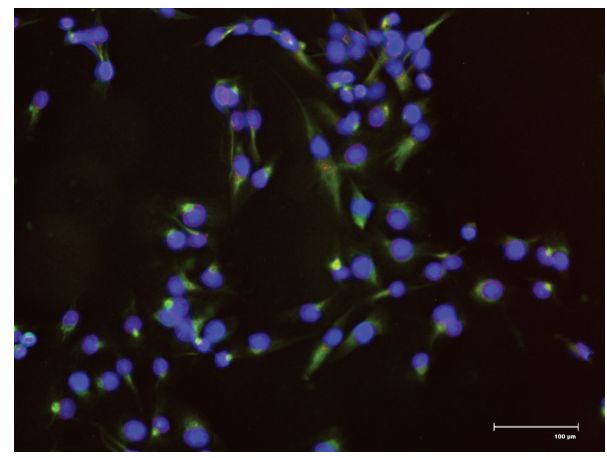

Merge

(b)

FIGURE 7: Immunochemical stains for DAPI (blue), vimentin (green), and CD44 (red) for adhered fibroblasts on CNTs and CNTs/SF polymer surfaces for $12 \mathrm{~h}$ of incubation to observe the morphology of the cells ((a) CNTs polymer surface; (b) CNTs/SF polymer surface; scale bar: $67 \mu \mathrm{m}$ for panel (a), $100 \mu \mathrm{m}$ for panel (b)). 


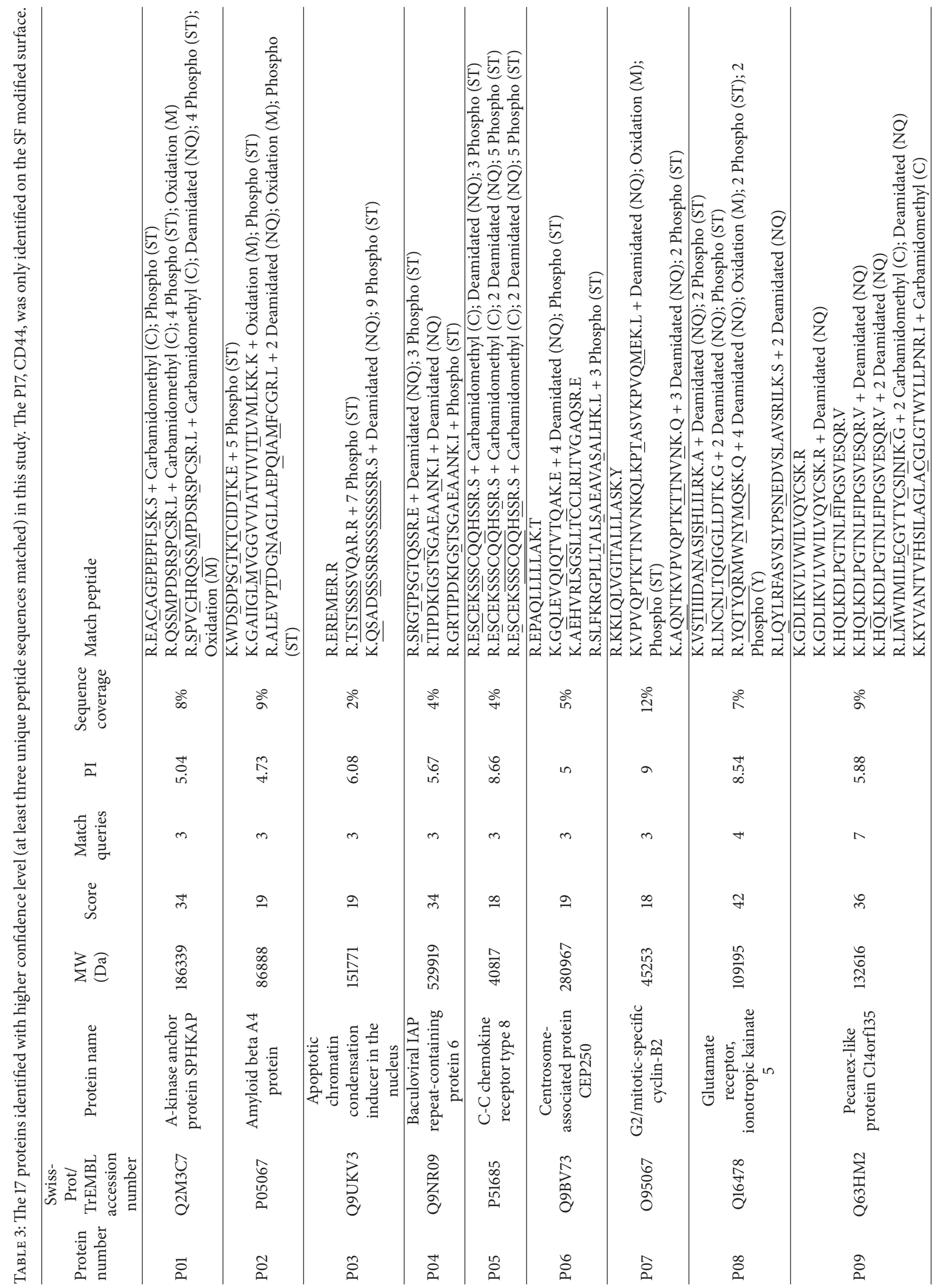




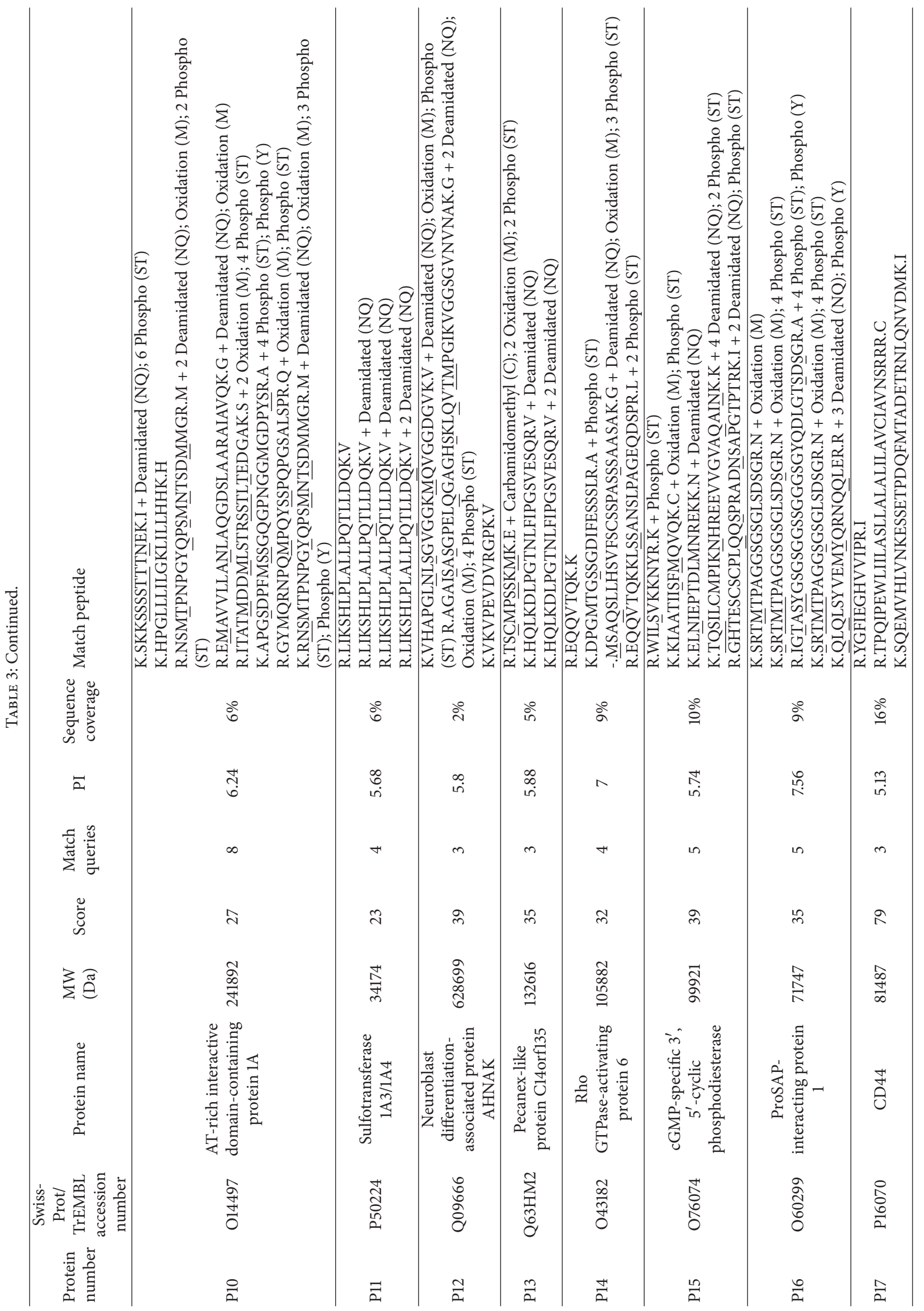


TABLE 4: The identified peptides and gene ontologies of CD44.

\begin{tabular}{lclll}
\hline Accession number & Protein name & Subcellular location & Biological process & Molecular function \\
\hline \multirow{2}{*}{ P16070 } & CD44 & $\begin{array}{l}\text { Membrane, cytoplasm, } \\
\text { Golgi apparatus }\end{array}$ & $\begin{array}{l}\text { Cell adhesion, cellular } \\
\text { response to fibroblast } \\
\text { growth factor stimulus }\end{array}$ & $\begin{array}{l}\text { Blood group antigen, } \\
\text { receptor, collagen } \\
\text { binding }\end{array}$ \\
\hline
\end{tabular}

CD44 is the receptor for hyaluronic acid (HA) and mediates cell-cell and cell-matrix interactions through its affinity for HA and possibly also through its affinity for other ligands such as osteopontin, collagens, and matrix metalloproteinases (MMPs).

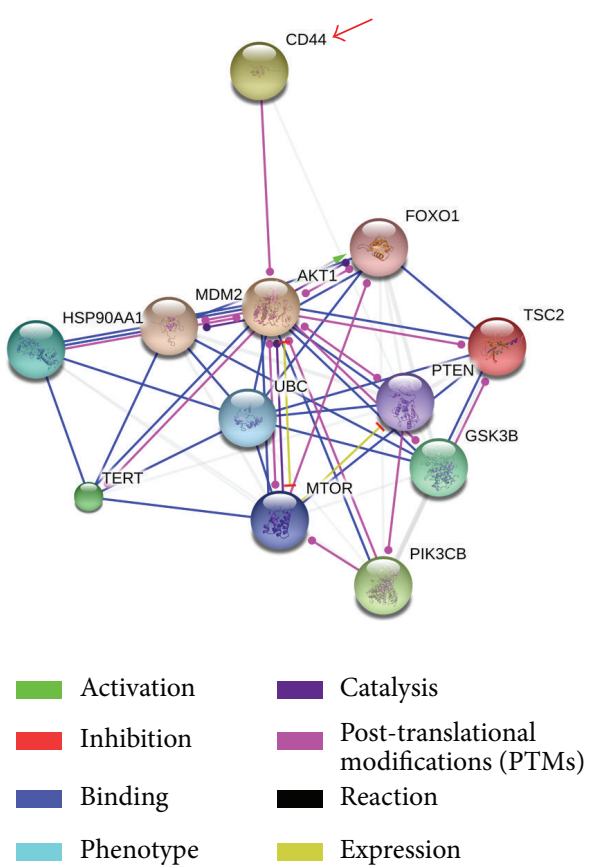

Figure 8: The CD44 protein-protein interaction pathways were performed by String 9.0 Web software. The CD44 can turn on the $\mathrm{PI} 3 \mathrm{~K} / \mathrm{AKT} / \mathrm{mTOR}$ pathway, which is responsible for the proliferation and is required for survival of the majority of cells.

by String 9.0 Web software (Figure 8). The CD44 can turn on the PI3 K/AKT/mTOR pathway, which is responsible for the proliferation and is required for survival of the majority of cells. The hypothesis of the mTOR pathway is that it acts as a master switch of cellular catabolism and anabolism, thereby determining the growth and proliferation of the cells. Activation of PI3 K/AKT/mTOR signaling through mutation of pathway components as well as through activation of upstream signaling molecules occurs in the majority of cells contributing to deregulation of proliferation, resistance to apoptosis, and changes in the metabolism characteristic of transforming cells.

As expected, the CNTs/SF polymer surface caused larger frequency shifts than the CNTs polymer surface. Indeed, the presence of SF on the surface supported in vitro cell adhesion, and SF participates importantly in cell proliferation [39]. In this study, the results were mutually consistent when using the BrdU cell proliferation assay and QCM techniques which were utilized to investigate the adhesions of fibroblasts to polymer surfaces that coated the electrodes. However, these methods are limited to the quantitative analysis of cell amount. Proteomic analysis provides a means for the largescale characterization of the differential expression of proteins from cells on modified surfaces. The mass spectrometrybased proteomics approach has many advantages, especially in identification of related proteins. Experimental results indicate that the CNTs/SF polymer surface may be able to activate several cell-material interaction pathways and promote cell adhesion. Consequently, previous unfamiliar proteins can be found and the interaction of cell-material may be established. The proteomic scheme was adopted to identify proteins with differential expression, which participate importantly in the adhesion of cells to material surfaces.

\section{Conclusions}

In this study, a biopolymer surface was formatted with SF. According to the results concerning fibroblasts that were stained with DAPI/vimentin/CD44, BrdU cell proliferation assay, and the frequency shifts that were determined using QCM, the numbers and mass of fibroblasts that adhered to the CNTs/SF polymer surface of electrodes were significantly higher than those of fibroblasts on other surfaces. The SF modified surface has been confirmed and improved the cell adhesion. To evaluate the responses of cellular proteins induced by SF-modified surfaces, mass spectrometry-based proteomics is adopted to analyze complex proteins of cell lysate and to profile proteins based on their associated cellsurface interactions. By utilizing proteomic approaches, it is indicated that the SF modified surface induces fibroblasts to express CD44 as an interactive protein between cell and material surface to enhance cell adhesion. Although the pathways of the interactions between CD44 and SF were unclear, the cell adhesion affected by CD44 was established. In summary, the functional groups of biomaterials may induce the secretion of proteins from cells. This study proposed a new approach for the detection of proteins to assess the response of fibroblasts to a material surface. Knowing the responses of cellular proteins induced by biomaterials may assist the development of applications in the immediate future.

\section{Novelty of the Study}

The preparation and characterization of silk fibroin modified surface were confined. The pathway of silk fibroin biopolymer surface induced cell membrane protein activation was identified by proteomic approaches. The silk fibroin biopolymer surface may induce and activate CD44 to enhance cell adhesion and proliferation. 


\section{Conflict of Interests}

The authors declare that there is no conflict of interests regarding the publication of this paper.

\section{Authors' Contribution}

Ming-Hui Yang and Tze-Wen Chung contributed equally to this work as first authors.

\section{Acknowledgments}

The authors thank the Center of Excellence for Environmental Medicine, Kaohsiung Medical University, for theassistance in protein identification, and S. Sheldon, MT(ASCP), of Oklahoma University Medical Center Edmond (retired), for fruitful discussions and editorial assistance before submission. This work was supported by research Grants NSC-102-3114-Y-492-076-023, NSC-1002320-B-037-007-MY3, and NSC-099-2811-E-224-002 from the National Science Council, MOHW103-TD-B-111-05 from Ministry of Health and Welfare, and NSYSUKMU 102-P006 from NSYSU-KMU Joint Research Project, Taiwan.

\section{References}

[1] B. Kasemo, "Biological surface science," Surface Science, vol. 500, no. 1-3, pp. 656-677, 2002.

[2] M. P. Lutolf and J. A. Hubbell, "Synthetic biomaterials as instructive extracellular microenvironments for morphogenesis in tissue engineering," Nature Biotechnology, vol. 23, no. 1, pp. 47-55, 2005.

[3] E. Cenni, F. Perut, and N. Baldini, "In vitro models for the evaluation of angiogenic potential in bone engineering," Acta Pharmacologica Sinica, vol. 32, no. 1, pp. 21-30, 2011.

[4] H. Wang, "Dispersing carbon nanotubes using surfactants," Current Opinion in Colloid and Interface Science, vol. 14, no. 5, pp. 364-371, 2009.

[5] L. Su, F. Gao, and L. Mao, "Electrochemical properties of carbon nanotube (CNT) film electrodes prepared by controllable adsorption of CNTs onto an alkanethiol monolayer selfassembled on gold electrodes," Analytical Chemistry, vol. 78, no. 8, pp. 2651-2657, 2006.

[6] N. A. Ayoub, J. E. Garb, R. M. Tinghitella, M. A. Collin, and C. Y. Hayashi, "Blueprint for a high-performance biomaterial: fulllength spider dragline silk genes," PloS ONE, vol. 2, no. 6, article e514, 2007.

[7] I. C. Um, H. Kweon, Y. H. Park, and S. Hudson, "Structural characteristics and properties of the regenerated silk fibroin prepared from formic acid," International Journal of Biological Macromolecules, vol. 29, no. 2, pp. 91-97, 2001.

[8] X. Zhang, M. R. Reagan, and D. L. Kaplan, "Electrospun silk biomaterial scaffolds for regenerative medicine," Advanced Drug Delivery Reviews, vol. 61, no. 12, pp. 988-1006, 2009.

[9] N. Guziewicz, A. Best, B. Perez-Ramirez, and D. L. Kaplan, "Lyophilized silk fibroin hydrogels for the sustained local delivery of therapeutic monoclonal antibodies," Biomaterials, vol. 32, no. 10, pp. 2642-2650, 2011.
[10] R. Rajkhowa, E. S. Gil, J. Kluge et al., "Reinforcing silk scaffolds with silk particles," Macromolecular Bioscience, vol. 10, no. 6, pp. 599-611, 2010.

[11] L. Soffer, X. Wang, X. Zhang et al., "Silk-based electrospun tubular scaffolds for tissue-engineered vascular grafts," Journal of Biomaterials Science, Polymer Edition, vol. 19, no. 5, pp. 653664, 2008.

[12] Y. Yang, X. Chen, F. Ding, P. Zhang, J. Liu, and X. Gu, "Biocompatibility evaluation of silk fibroin with peripheral nerve tissues and cells in vitro," Biomaterials, vol. 28, no. 9, pp. 1643-1652, 2007.

[13] C. Li, C. Vepari, H.-J. Jin, H. J. Kim, and D. L. Kaplan, "Electrospun silk-BMP-2 scaffolds for bone tissue engineering," Biomaterials, vol. 27, no. 16, pp. 3115-3124, 2006.

[14] Y. Wang, D. J. Blasioli, H.-J. Kim, H. S. Kim, and D. L. Kaplan, "Cartilage tissue engineering with silk scaffolds and human articular chondrocytes," Biomaterials, vol. 27, no. 25, pp. 44344442, 2006.

[15] F. G. Omenetto and D. L. Kaplan, "New opportunities for an ancient material," Science, vol. 329, no. 5991, pp. 528-531, 2010.

[16] M. R. Wilkins, J.-C. Sanchez, K. L. Williams, and D. F. Hochstrasser, "Current challenges and future applications for protein maps and post-translational vector maps in proteome projects," Electrophoresis, vol. 17, no. 5, pp. 830-838, 1996.

[17] S. Oughlis, S. Lessim, S. Changotade et al., "Development of proteomic tools to study protein adsorption on a biomaterial, titanium grafted with poly(sodium styrene sulfonate)," Journal of Chromatography B: Analytical Technologies in the Biomedical and Life Sciences, vol. 879, no. 31, pp. 3681-3687, 2011.

[18] J. Sund, H. Alenius, M. Vippola, K. Savolainen, and A. Puustinen, "Proteomic characterization of engineered nanomaterialprotein interactions in relation to surface reactivity," ACS Nano, vol. 5, no. 6, pp. 4300-4309, 2011.

[19] D. Lavigne, L. Guerrier, V. Gueguen et al., "Culture of human cells and synthesis of extracellular matrix on materials compatible with direct analysis by mass spectrometry," Analyst, vol. 135, no. 3, pp. 503-511, 2010.

[20] M. H. Yang, S. B. Jong, C. Y. Lu et al., "Assessing the responses of cellular proteins induced by hyaluronic acid-modified surfaces utilizing mass spectrometry-based profiling system: overexpression of CD36, CD44, CDK9, and PP2A," Analyst, vol. 137, no. 21, pp. 4921-4933, 2012.

[21] T.-W. Chung, T. Limpanichpakdee, M.-H. Yang, and Y.-C. Tyan, "An electrode of quartz crystal microbalance decorated with CNT/chitosan/fibronectin for investigating early adhesion and deforming morphology of rat mesenchymal stem cells," Carbohydrate Polymers, vol. 85, no. 4, pp. 726-732, 2011.

[22] K. A. Marx, "Quartz crystal microbalance: a useful tool for studying thin polymer films and complex biomolecular systems at the solution-surface interface," Biomacromolecules, vol. 4, no. 5, pp. 1099-1120, 2003.

[23] A. Pomorska, D. Shchukin, R. Hammond, M. A. Cooper, G. Grundmeier, and D. Johannsmann, "Positive frequency shifts observed upon adsorbing micron-sized solid objects to a quartz crystal microbalance from the liquid phase," Analytical Chemistry, vol. 82, no. 6, pp. 2237-2242, 2010.

[24] M. Zhang, L. Su, and L. Mao, "Surfactant functionalization of carbon nanotubes (CNTs) for layer-by-layer assembling of CNT multi-layer films and fabrication of gold nanoparticle/CNT nanohybrid," Carbon, vol. 44, no. 2, pp. 276-283, 2006.

[25] E. L. Bakota, L. Aulisa, D. A. Tsyboulski, R. B. Weisman, and J. D. Hartgerink, "Multidomain peptides as single-walled carbon 
nanotube surfactants in cell culture," Biomacromolecules, vol. 10, no. 8, pp. 2201-2206, 2009.

[26] S. J. Lee, S. Y. Kim, and Y. M. Lee, "Preparation of porous collagen/hyaluronic acid hybrid scaffolds for biomimetic functionalization through biochemical binding affinity," Journal of Biomedical Materials Research-Part B Applied Biomaterials, vol. 82, no. 2, pp. 506-518, 2007.

[27] R. R. Pochampally, J. R. Smith, J. Ylostalo, and D. J. Prockop, "Serum deprivation of human marrow stromal cells (hMSCs) selects for a subpopulation of early progenitor cells with enhanced expression of OCT-4 and other embryonic genes," Blood, vol. 103, no. 5, pp. 1647-1652, 2004.

[28] B. Lehner, B. Sandner, J. Marschallinger et al., "The dark side of BrdU in neural stem cell biology: detrimental effects on cell cycle, differentiation and survival," Cell and Tissue Research, vol. 345, no. 3, pp. 313-328, 2011.

[29] S. T. Becker, T. Douglas, Y. Acil et al., "Biocompatibility of individually designed scaffolds with human periosteum for use in tissue engineering," Journal of Materials Science: Materials in Medicine, vol. 21, no. 4, pp. 1255-1262, 2010.

[30] P. A. Harper, P. Brown, and R. L. Juliano, "Fibronectinindependent adhesion of fibroblasts to extracellular matrix material: partial characterization of the matrix components," Journal of Cell Science, vol. 63, pp. 287-301, 1983.

[31] W. M. Petroll, L. Ma, and J. V. Jester, "Direct correlation of collagen matrix deformation with focal adhesion dynamics in living corneal fibroblasts," Journal of Cell Science, vol. 116, no. 8, pp. 1481-1491, 2003.

[32] M. Miron-Mendoza, J. Seemann, and F. Grinnell, “Collagen fibril flow and tissue translocation coupled to fibroblast migration in 3D collagen matrices," Molecular Biology of the Cell, vol. 19, no. 5, pp. 2051-2058, 2008.

[33] T. J. Fuja, E. M. Ostrem, M. N. Probst-Fuja, and I. R. Titze, "Differential cell adhesion to vocal fold extracellular matrix constituents," Matrix Biology, vol. 25, no. 4, pp. 240-251, 2006.

[34] M. Dimitrijevic-Bussod, V. S. Balzaretti-Maggi, and D. M. Gadbois, "Extracellular matrix and radiation G1 cell cycle arrest in human fibroblasts," Cancer Research, vol. 59, no. 19, pp. 48434847, 1999.

[35] S. Goodison, V. Urquidi, and D. Tarin, "CD44 cell adhesion molecules," Molecular Pathology, vol. 52, no. 4, pp. 189-196, 1999.

[36] B. Ghosh, Y. Li, and S. A. Thayer, "Inhibition of the plasma membrane $\mathrm{Ca}^{+2}$ pump by CD44 receptor activation of tyrosine kinases increases the action potential afterhyperpolarization in sensory neurons," Journal of Neuroscience, vol. 31, no. 7, pp. 2361-2370, 2011.

[37] H. Ponta, L. Sherman, and P. A. Herrlich, "CD44: from adhesion molecules to signalling regulators," Nature Reviews Molecular Cell Biology, vol. 4, no. 1, pp. 33-45, 2003.

[38] H. Ponta, D. Wainwright, and P. Herrlich, "The CD44 protein family," International Journal of Biochemistry and Cell Biology, vol. 30, no. 3, pp. 299-305, 1998.

[39] J. R. E. Fraser, T. C. Laurent, and U. B. G. Laurent, "Hyaluronan: its nature, distribution, functions and turnover," Journal of Internal Medicine, vol. 242, no. 1, pp. 27-33, 1997. 


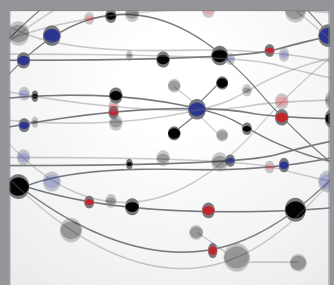

The Scientific World Journal
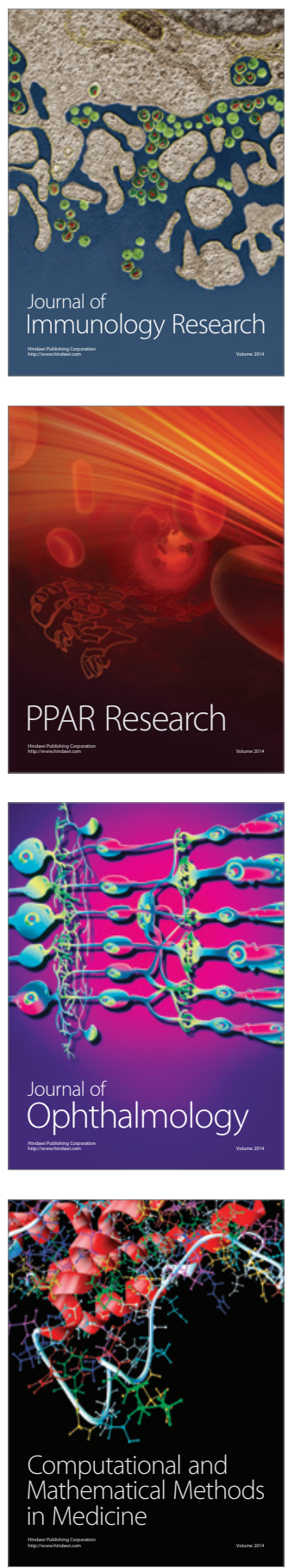

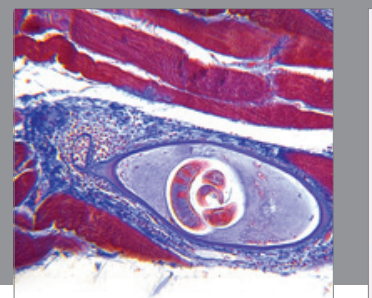

Gastroenterology

Research and Practice
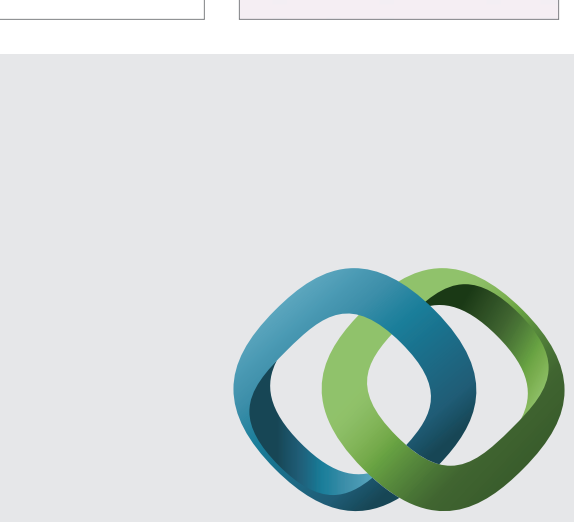

\section{Hindawi}

Submit your manuscripts at

http://www.hindawi.com
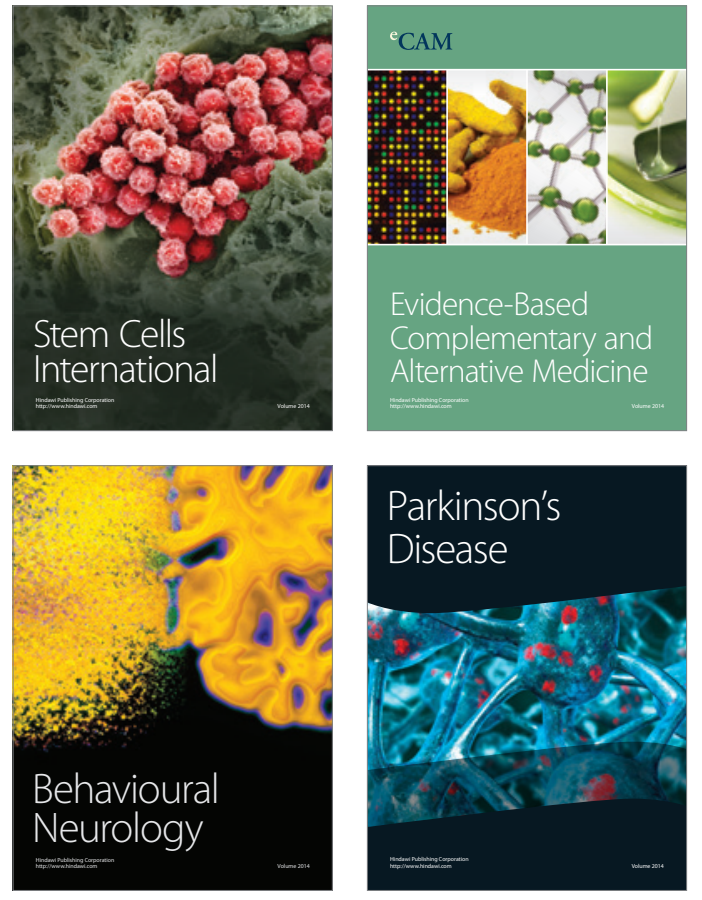
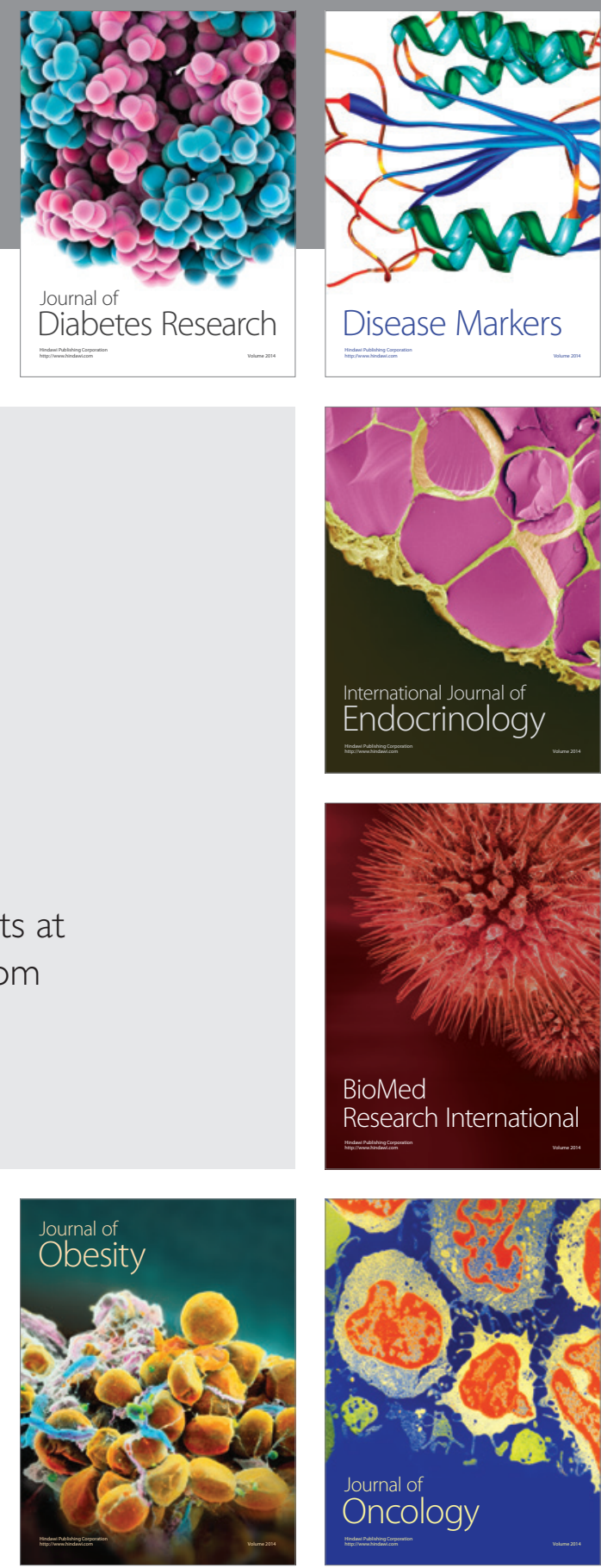

Disease Markers
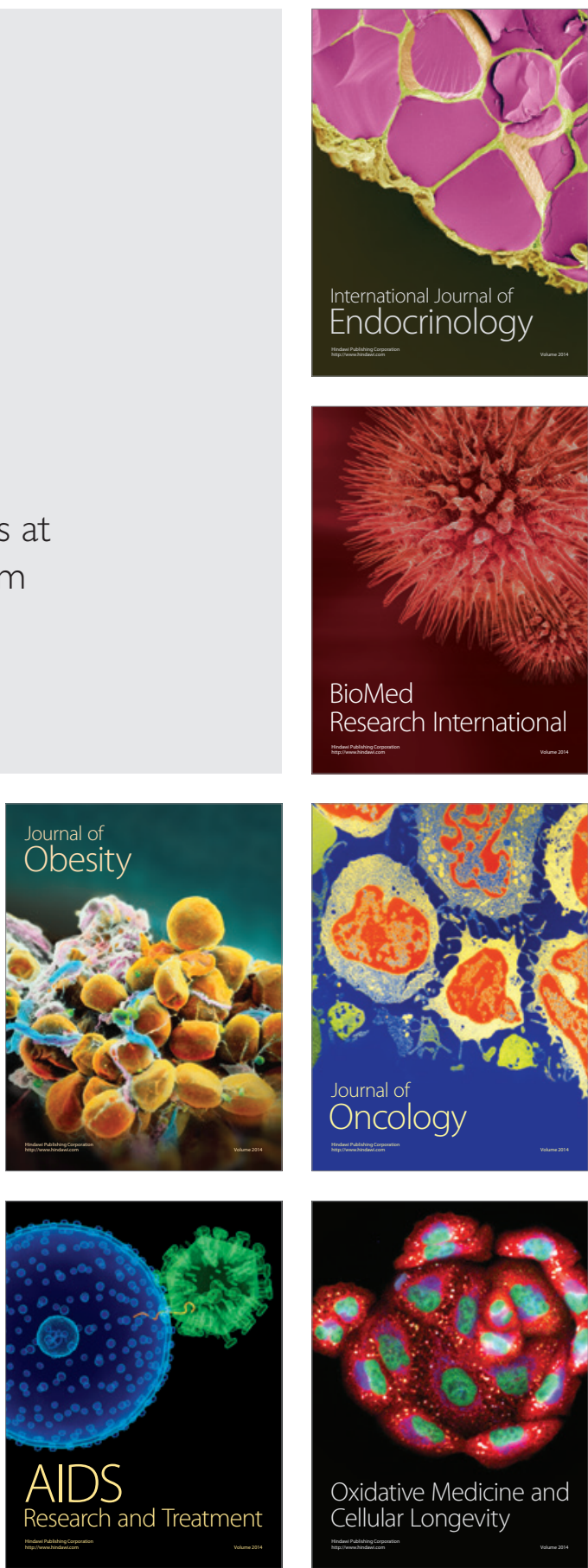